\title{
How to Help Children and Adolescents with Austism Sprectrum Disorder during Covid-19 Pandemic
}

Galeti FS ${ }^{1,2,3}$, Arvigo MC $^{2}$, Berardineli FP ${ }^{3}$, Felippette TRB and Bordini $\mathrm{D}^{3}$

${ }^{1}$ Brazilian Institute of Psychopharmacology and Pharmacogenetics (BIPP)

${ }^{2}$ Autism Spectrum Disorder Clinic- Mackenzie Presbyterian University (UPM)

${ }^{3}$ Federal University of São Paulo (Unifesp)
"Correspondence author

Fabricia Signorelli Galeti

Psychiatrists

Specialized in child and adolescent psychiatry at the State University of Campinas

Brazil

Submitted : 23 April 2020 ; Published : 18 May 2020

\begin{abstract}
The Autism Spectrum Disorder(ASD) are distinguished by persistent deficits in social communication and social interaction and restricted and repetitive patterns of behavior. Coronaviruses are an extremely common cause of colds and other upper respiratory infections. COVID-19, short for “coronavirus disease 2019”. The fast spread of the virus that causes COVID-19 has sparked alarm worldwide. The World Health Organization (WHO) has declared this rapidly spreading coronavirus outbreak a pandemic. Most of the countries around the world are adopting social distancing to slow the spread of coronavirus. There are several possible impacts of this pandemic on the daily lives of individuals with ASD, such as worsening of dysfunctional behaviors and regression of skills already acquired in different domains of development due to the social isolation. The objective of this article is to provide guidance to parents, health andeducation professionals that liveor work with ASD individuals during the social isolation, on how to manage interventions that can be executed in the home environment, like remote training in language and social communication skills, behavioral strategies and sensory integration activities.
\end{abstract}

\section{Introduction}

Autism Spectrum Disorder are distinguished by persistent deficits in social communication and social interaction, in socioemotional reciprocity and nonverbal communicative behaviors, difficulties in various domains of development and adaptive functions, maintenance and understanding of relationships and restricted and repetitive patterns of behavior, interests and activities, such as motor movements or stereotyped speech, inflexibility to changes in routines and behavioral changes [1].

According to estimates by the Autism and Developmental Disabilities Monitoring Network, of the Centers for Disease Control and Prevention (03/27/2020) 1 in 54 children is identified with ASD and the disorder affects all racial, ethnic and socioeconomic groups [2].

Coronaviruses are an extremely common cause of colds and other upper respiratory infections. COVID-19, short for "coronavirus disease 2019," is the official name given by the World Health Organization (WHO) to the disease caused by this newly identified coronavirus. Some people infected with the virus have no symptoms. When the virus causes symptoms, common ones include fever, body ache, dry cough, fatigue, chills, headache, sore throat, loss of appetite, and loss of smell. In some people, COVID-19 causes more severe symptoms like high fever, severe cough, and shortness of breath, which often indicates pneumonia. COVID-19 affects brain function in some people. Specific neurological symptoms seen in COVID-19 patients include loss of smell, inability to taste, muscle weakness, tingling or numbness in the hands and feet, dizziness, confusion, delirium, seizures, and stroke. In addition, some people have gastrointestinal (GI) symptoms, such as loss of appetite, nausea, vomiting, diarrhea, and abdominal pain or discomfort associated with COVID-19 [3].

The fast spread of the virus that causes COVID-19 has sparked 
alarm worldwide. The World Health Organization (WHO) has declared this rapidly spreading coronavirus outbreak a pandemic, and countries around the world are grappling with a surge in confirmed cases. Most of the countries around the world are adopting social distancing to slow the spread of coronavirus. Meanwhile, scientists are exploring potential treatments and are beginning clinical trials to test new therapies and vaccines. And hospitals are ramping up their capabilities to care for increasing numbers of infected patients [4].

The official website of the World Health Organization (WHO) published a statement from WHO Director-General, Tedros Adhanom Ghebreyesus that reinforced the importance of confinement as a combat measure during the pandemic. Ghebreyesus mentioned that it is essential to ensure that many countries are well equipped to detect, test, isolate and treat cases and identify contacts, I see that this is happening in many countries, despite limited resources [5].

Many countries are asking people to stay at home and reduce population movement, which can help limit the spread of the virus. Faced with this scenario of uncertainties, there are several possible impacts of this pandemic on the daily lives of individuals with ASD, such as worsening of dysfunctional behaviors and regression of skills already acquired in different domains of development due to the social isolation that leads to routine changes and interruption of therapeutic processes.

We are living a unique moment in the world. Social isolation is one of the unanimous recommendations put into practice currently, but how will it affect autistic patients on a daily basis who demand countless hours of weekly interventions with multiple professionals? How can we not risk the regression of skills with all the social restrictions essential for our survival? How to ask families to take responsibility for multiple daily stimulation?. Most caregivers are overwhelmed with having to take care of their children out of school, monitoring educational activities at home (online classes and chores), taking care of household chores and meals as well as working from home so as not to lose their jobs that support the treatments... when they are possible and accessible.

Most autistic patients have experienced a sudden change in routine, they may be more agitated, insomniac, impatient or more sensorially unregulated. Others are calmer and more comfortable in their homes, without so many demands, without so many orders from professionals and social requests imposed by the usual routine of school and therapies. A new organization in each of their homes is being created, given the possibilities of each family and as mental health professionals we have to be aware of this and respect the moment of adaptation on a case-by-case basis.

The importance of parents acting as agents/mediators is unquestionable in the treatment of their children with the guidance of specialized professionals during this period. It may be the only possibility for some cases. However, professionals need to weigh and balance the suggested demands well otherwise they may feel even more overwhelmed and a failure in this mission.

The most important of all is to be able to balance a possible and healthy routine for everyone involved because we have no perspective of when all this will end and we cannot leave these patients without treatment for a long time.

Each autistic person is unique, there is no ready recipe for each family, we will have to make adjustments and adaptations individually.

\section{Remote Training in Language and Social Communication} Skills

Children and teenagers with ASD commonly have different levels of language impairments. Some of them, for different reasons, take a long time to acquire and improve the emissive language. Clearly, this moment of lockdown, without intervention is a reason to let the parents anxious and afraid of possible regressions in language and communication skills, which is already acquired.

For a long time, it was believed that children with ASD did not have enough skills to talk and acquire and develop functional emissive language. The individual with autism was popularly known as that person who lives in an isolated world, in a corner of the house, unable to communicate and interact with others, who exhibited inappropriate behaviors and repetitive and stereotyped movements of hands and body. However, in the last decade, this idea has undergone strong changes and recent researches indicate that more than $60 \%$ of individuals with ASD are able to acquire functional emissive language [6].

Much of this change is due to advances of knowledge, the training of professionals, and the development of assessment tools that are more sensitive to signs of ASD. Nowadays is known that some behavioral signs of ASD emerge early in the first years of life, around 9 to 18 months ${ }^{[7]}$. Identifying early signs of autism in children, before 3 years of age, is crucial to ensure timely access to early intervention and needed services, leading to a better prognosis and improving functional outcomes, increasing chances of developing emissive language $[7,8]$.

Communication and language impairments in ASD are many and, as well as other characteristics related to this disorder, vary between cases both in severity and in incidence. The delay in language acquisition is one of the most common early signs, yet parents often report their concerns about their children's language development $[9,10]$. However, the emergence of speech in children with ASD tends to be slower than their typical peer because of the deficits on other skills that precede emissive language.

Amid these skills, joint attention and the different behaviors related to it, imitation and playing, both functional and symbolic, are some of the precursors and prompts of language acquisition and development, as they are directly related to 
social interaction and social communication [11]. ASD is a neurodevelopmental disorder that leads to deficits, precisely, in interaction and social communication, associated with repetitive behavior patterns [1]. Therefore, intervention programs that are effective should emphasize the maximization of driving skills of functional language and social communication.

Breaking behavior patterns and implementing new skills is a task that requires time, effort, repetition, and dedication. In this moment of lockdown, it is totally understandable that parents are feeling anxious and stressed by the abrupt change and by the interrupt in the intervention process since many of the skills are still in the process of learning and no stimulation can lead to setbacks in the acquisition process. However, maintaining newly acquired or learned skills is not as complicated as it seems and can be implemented in the daily routine of families at the present time and maintained throughout the child's development process.

The implementation of the routine should be carried out under the supervision of a specialized professional, in person or, given the current conditions, through teleconsultation. But this may not be the reality for many families around the world due to the difficulty of accessing online media or even the difficulty in adapting to a distance relationship with the professional. The reasons are numerous and all are justified.

But then, how can we maintain skills in the development and foster the acquisition of children's language at home during this period of lockdown? Here are some tips [12].

Encourage the children to play, organize a quiet space, free from over-stimulation. If you choose to play with the child in the room, for example, turn off the TV or any other sound device and/or visual. Choose items that catch the child's attention and gradually convince her/him to sit or stay close to you. Through playful activities, it is possible to work different skills.

Eye Contact and Joint Attention

Choose toys with sounds or lights, or which move. Place the toy in the child's field of vision and then bring it to your face, making her/ him look at you. Stop the operation of the toy and make faces or smile, playing with the child.
Creating cause and effect situations

Imitate the sounds that the child already makes, such as vocalizations while she/he is playing with or manipulating an object. Observe how she/he gets into your game and, gradually, increase the frequency of the sounds, making some moments of silence for the child to fill them with her/him sounds or even with new ones.
Play with soap bubbles.

Make some bubbles to get the child's attention, then stop for a while. Wait until she/he looks at you, then

Encourage the child to comb your hair, puts on your makeup, or draw pictures with paint on your face. Make faces and varying and different sounds, or play hide-and-seek.

(1)
make more balls.

Play about feed the dolls and animal toys, to put them in the miniature car for a walk, to make the airplane fly, always making many sounds, and giving time to the child to try to imitate.

Build a tower out of toy blocks, of shoe boxes or plastic cups. Count to 3 or make a sound before dropping it. Repeat the action, but this time, wait for the child to look at you, then make the sound and knock the tower down again.

These are some activities that can be developed at home, mediated by parents and other family members, based on the development of functional and symbolic play, improving the interaction between the child and the adult. However, it is important to remember that the activities mediated by parents at home, although they bring great benefit, should be understood as part of the child's therapeutic process and should not replace the clinical intervention performed by the specialized professional.

Online therapy guided by the speech therapist, for cases of ASD, should also prioritize the child's interaction with parents, through parental training. Parental training represents a collaborative work method that aims to guide and train parents, aiming to learn more effective ways to deal with certain behaviors and so that they can intervene in a way that improves the development of their children's communication $[13,14]$.

The remote intervention plans, as with the face-to-face intervention, must be individual, respecting the child's skills and deficits, and constructed based on the assessment data.

Thus, through direct interventions, in a synchronous manner, that is, with the professional watching the parent/child interaction and providing guidance in real-time, or indirectly, asynchronously, when the parents record the interaction and the professional performs the guidance at another time, the family is being instrumentalized and empowered to deal with different aspects of the child's skills acquisition.

In sum, regardless of the difficulties presented by parents in dealing with their children's disabilities and behaviors, with adequate guidance and good planning, everyone can carry out the interventions and, thus, guarantee the children's success [13].

\section{Behavioral Strategies during the Social Isolation}

In the last few days, there have been many changes; people have had to deal with the sudden, the new and the unknown. Schools and clinics shutdowns, besides other social routines. Classes and work have been conducted virtually; broken 
bounds with our loved ones and the fear of contamination have generated fear, anxiety and stress.

Individuals with autism take longer to process news and changes, needing more support. There are many challenges, not just for them, but for families and for us as a team. Suddenly we had to reinvent ourselves, while still offering reception and technical possibilities for adaptations and habituations, minimizing stress, anxiety and depression.

Thus, we have included in this material some examples of accessible resources to help families and caregivers implement strategies quickly and easily, presenting different tips and complexity levels to make the material meaningful among different ages and abilities. Bearing in mind that our work is done based on each patient's profile, through repertoire assessments, constant functional analysis and technologies from Behavioral Analytical Science, the child's sensory profile is composed by standardized questionnaires answered by the parents, school and also by assessment instruments that validate such information $[15,16]$. Here we present some ideas and visual models of what can be adapted depending on each child's profile.

\section{Familly Heallth:}

While taking care of our children, we need to make time to take care of ourselves. It is natural to have fear, and to feel anxious and sad. Remember to keep a few moments to yourself, in which you can do something to recharge $[17,18]$ Examples of activities that help us recharge:

- $\quad$ Try to sleep at least 6 hours per night;

- Eat nutritious foods;

- Do light exercising;

- Get involved with a hobby;

- Share something good that have happened;

- Pray, meditate or do a relaxing activity;

- Help a friend;

- Read a book and watch some movies/TV shows that make you happy.

Remember: When your body releases stress hormones, certain parts of the brain are impaired

(For example, problem solving, communication, critical thinking). It is imperative that you exercise in order to remain emotionally balanced.

When waves of despair approach you, do the following exercise, which will help you focusing in the present moment:

- Recognize FIVE things you see around yourself...

- Recognize FOUR things you can touch around yourself...

- Acknowledge THREE things you hear...

- Recognize TWO things you can smell...

- Recognize ONE thing you can taste...

- Get busy with the task that is in front of you.
2. Possible Behavioral Changes and Transition to FaceTo-Face Activities:

People with autism can get used to certain routine patterns and present some difficulties in solving problems, in which they require cognitive flexibility; therefore, social isolation can lead to disorganization and side effects. Such changes may impact on some behavioral patterns, for instance: sleeping and feeding habits; increase in repetitive and stereotyped behaviors; agitation; and irritation. In the first behavioral changes, families should look for members involved in the child's treatment, such as the responsible physician and the therapeutic team. It is important to work with the person with autism that there will be a return to school and to therapeutic activities after coronavirus most critical period, since it is possible that this individual shows avoidance in returning to usual activities, due to the confinement time. For that, it is necessary:

- To make social stories;

- Videos of people involved in the school and therapeutic process, with statements related to the return;

- Combined routine boards.

\section{Understanding:}

Comprehensive communication is one of the deficits showed up in the ASD diagnosis, with severity levels regarding each individual's behavioral profile. Understanding COVID-19 virus is necessary for the development of some repertoires, such as reducing the exposure and contamination risk. For this to become effective, the adult must use a clear and objective language, concretely describing for the child, and explaining that coronavirus is a germ type $[19,20]$. These germs are very small and when they get inside of your body, they can "get you sick":

- Reading social stories to/with the individual with autism regularly during several days is important to reinforce learning about the subject;

- If necessary, review and adjust the story according to the child's circumstances and specificities, in addition to the guidelines recommended by the health agency;

- Offer written activities, with keywords, through dotted lines, dictations or copying. Word suggestions: germ; health; stay home; wash your hands;

- Use visual support to provide guidance on specific actions and behaviors to prevent coronavirus, for example, about how to wash your hands; home activities; playing at home; greeting people at distance with gestures; and time passing;

- Use a timer (sonore clue) for task time, play time and engaged time in reinforcement options. Thus, the routine will be guaranteed! 
Examples:
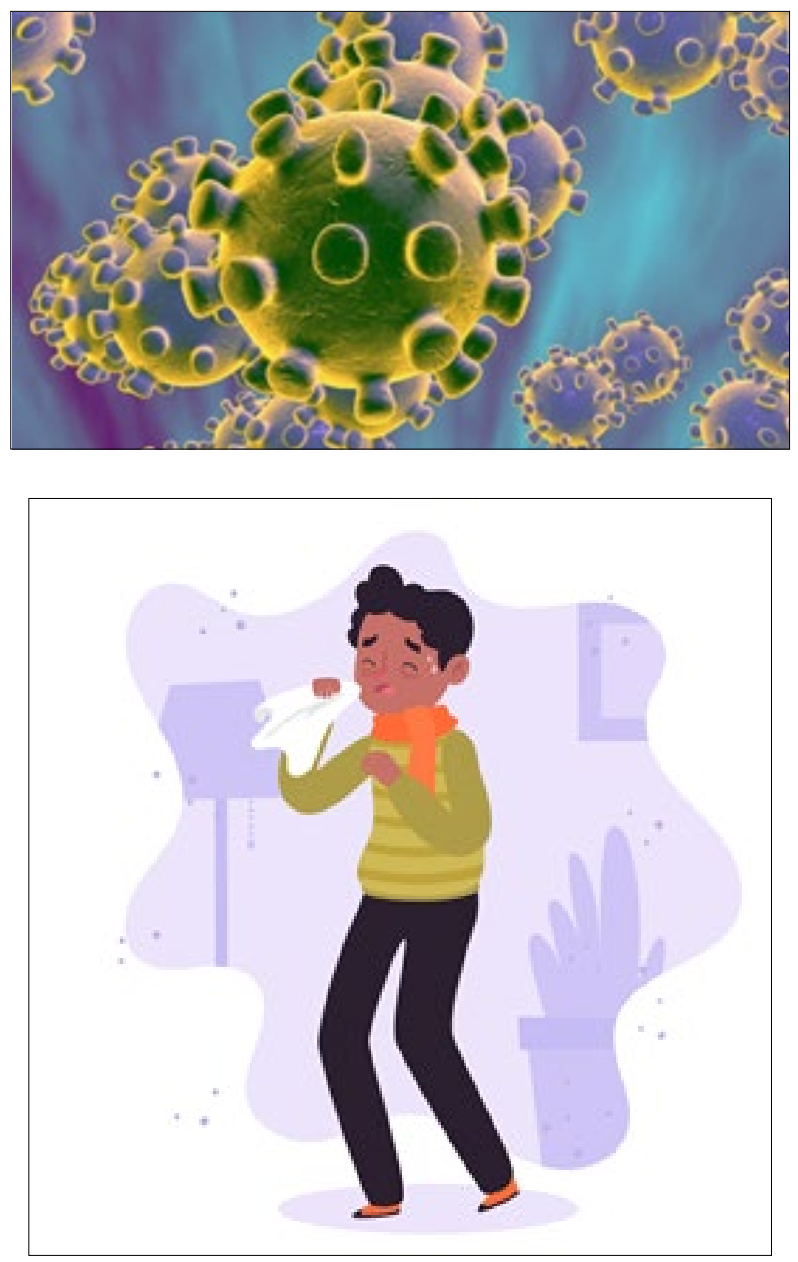

The coronavirus is a very small germ. It likes to travel to many places and people fail to see it.

It hides in people's clothes and makes them sick.

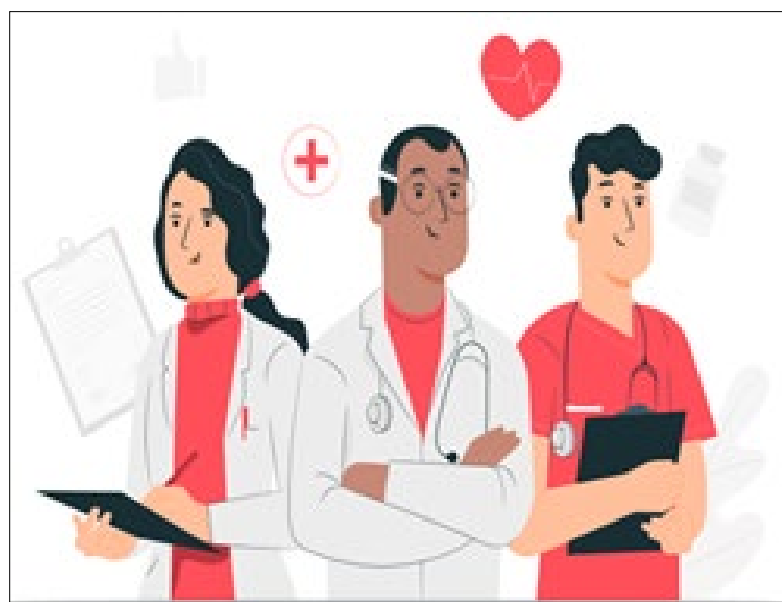

Doctors, nurses and scientists have been working to help people with medicines and vaccines.

But there are no remedies yet, so we need to protect ourselves at home.

So, for now, I am doing my school and therapy activities at home. I also have games; readings; recipes; and motor activities.
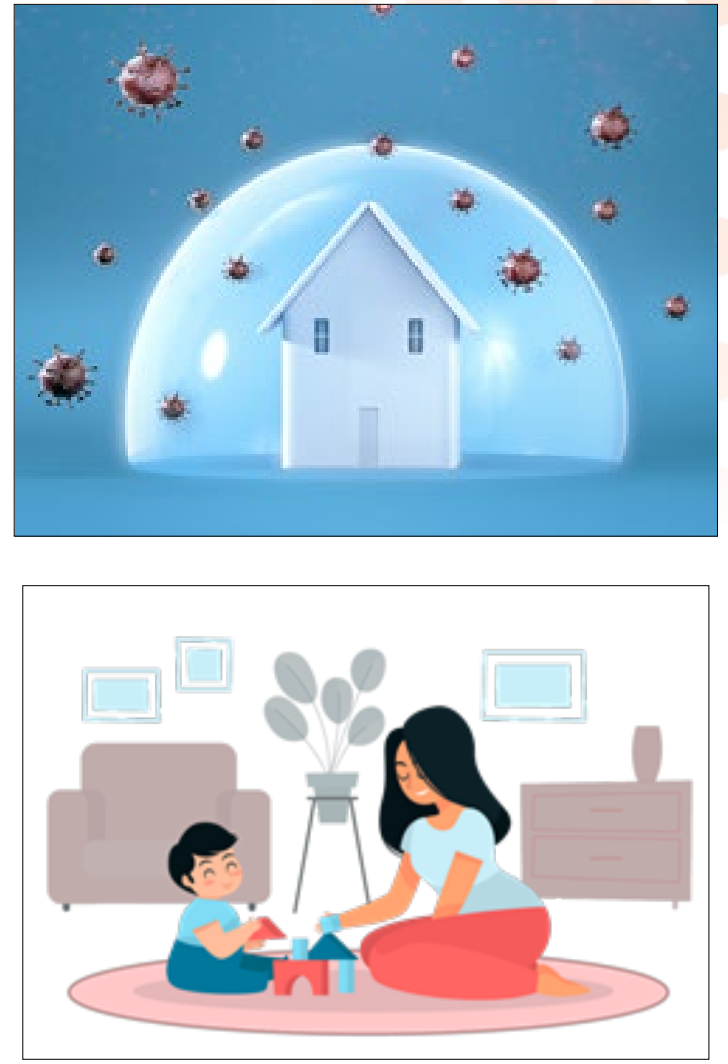

Timer Visual Calendars
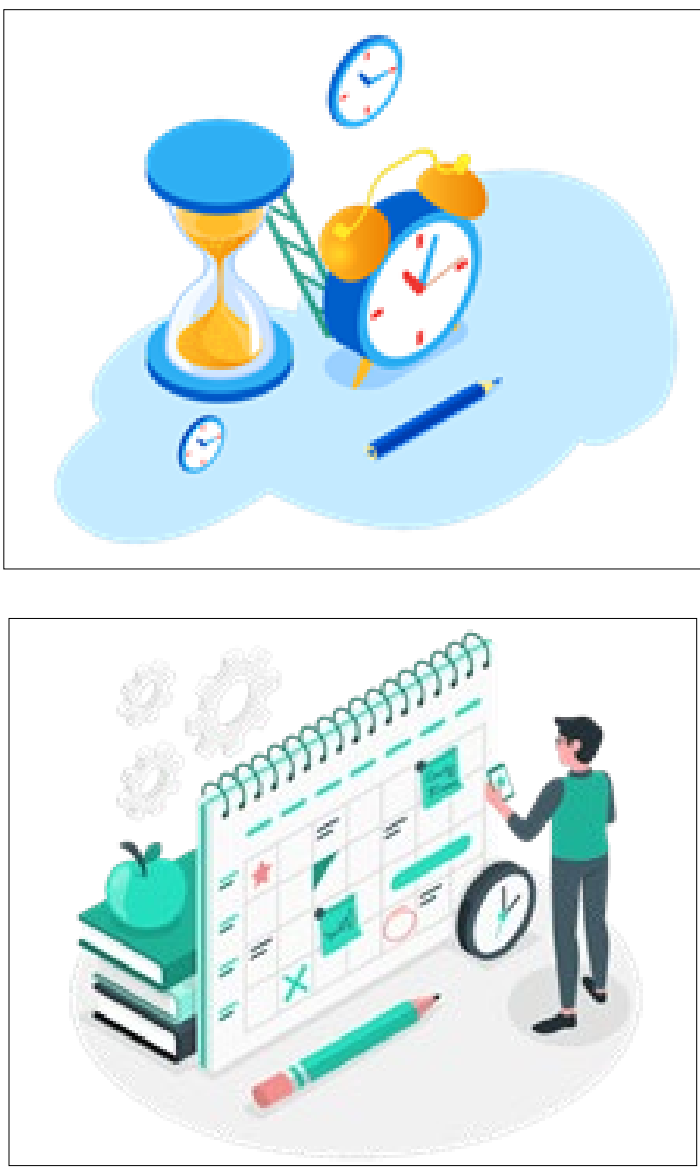
Greetings Wash Your Hands
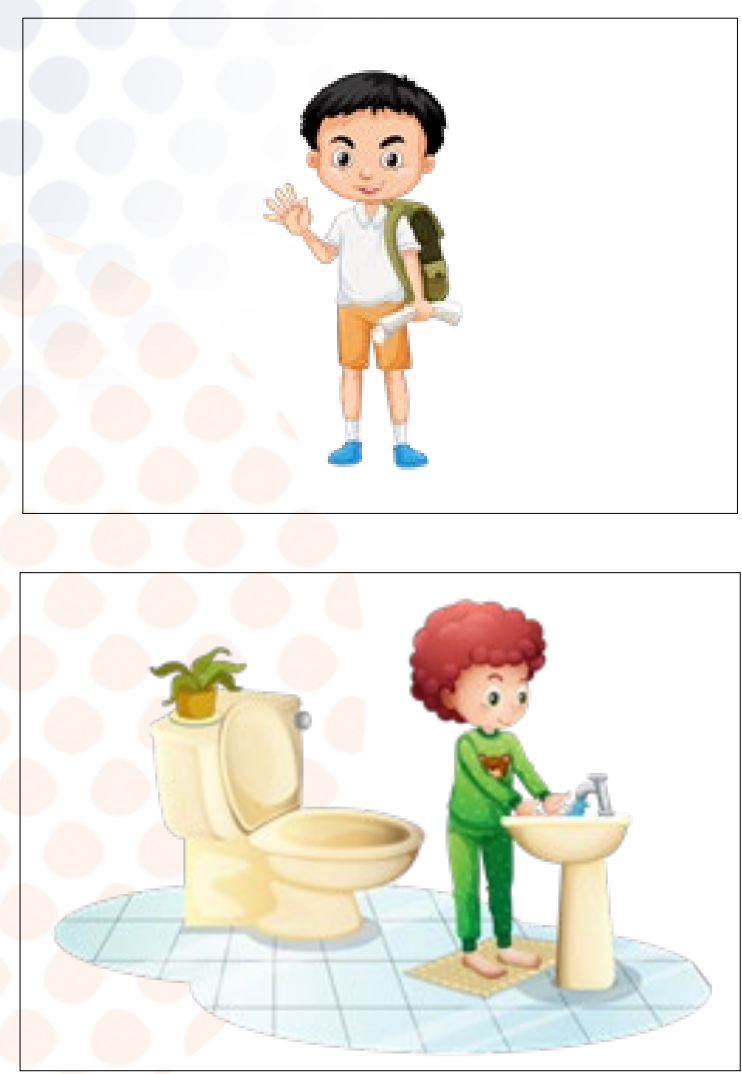

4 Expression:

It is common for the autistic community to show difficulties related to expressive communication, especially in an articulate and comprehensive way. It is extremely important to provide an opportunity for them to express themselves in an appropriate and functional way. Many of them adopt tantrum as a communication tool and the consequence offered by the environment can reinforce this behavior [19,20].

Therefore, working in functional and augmentative communication has been the greatest challenge for researchers and therapists. Here are some tips to boost this skill:

- Generate dialogue opportunities on the subject, through questions and answers, that is, the adult can simulate an interview with family members. He will prepare, with the child/teenager, a script, that can be practiced through video calls;

- Ask the child to retell the social story about coronavirus and set up other social stories with it. They can promote the creation of a portfolio, to work with time passing. Ir order to do so, they can do searches on Google; look for images; print; write; cut and paste;

- Propose role play activities (dramatizations related to the story);

- Drawings on the current context and feelings involved.
DID YOU HEAR ABOUT ME? I CAN UNDERSTAND HOW YOU FEEL..
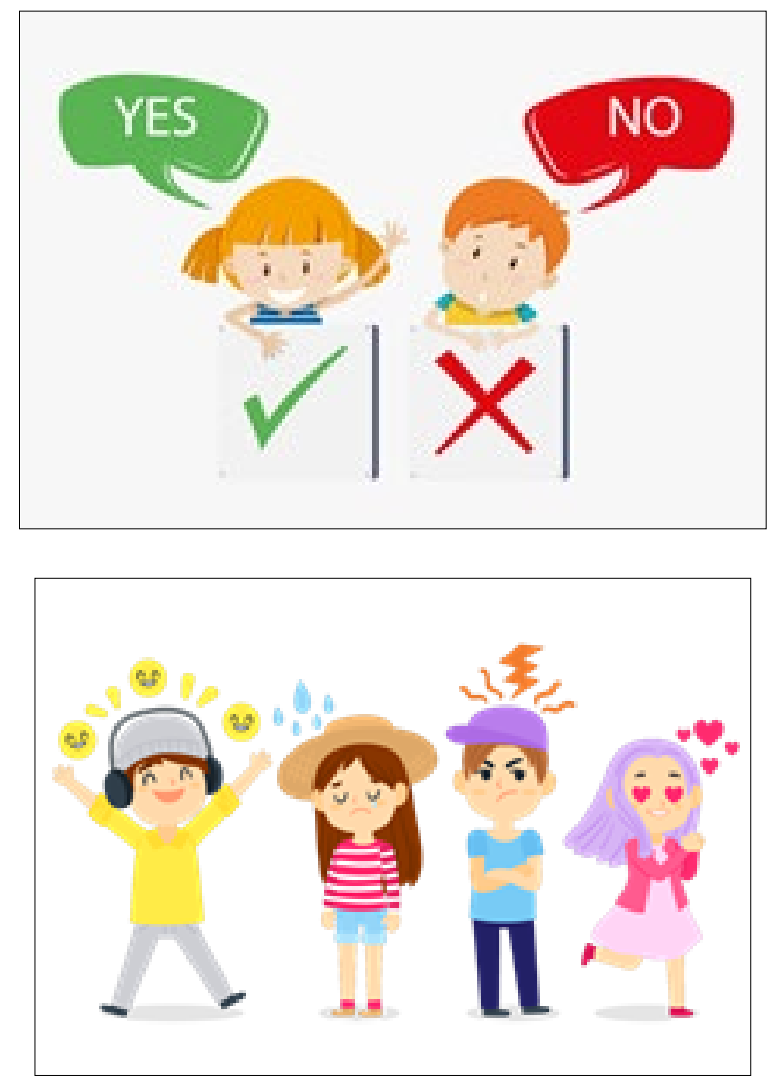

HOW DO YOU FEEL WHEN YOU HEAR MY NAME?

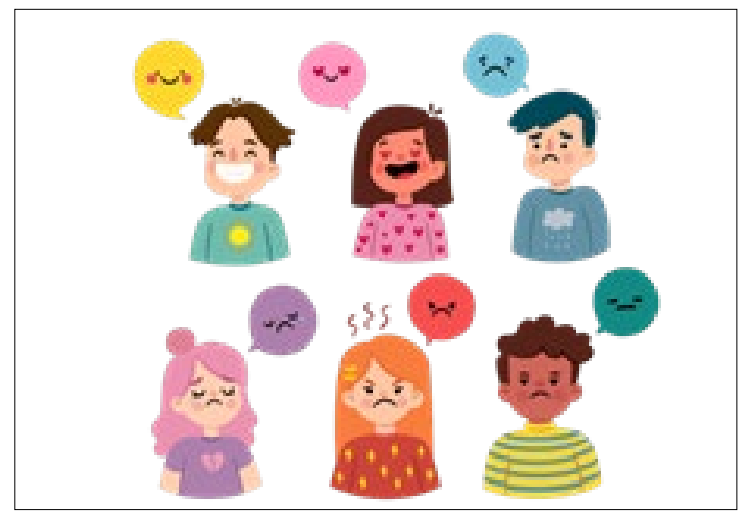

5 ADAPTIVE BEHAVIOR

It is important that the environment offers, to individuals with autism, opportunities and mediations for self-management and self-care, in order to reduce anxiety and so that they can calm themselves down in difficult times $[21,22]$.

- Reward board, or self-management board;

- Earmuffs use;

- Swing use;

- Listen to music;

- We will cover self-regulation tips in the next topic, in which the child learns how to use both internal and external mechanisms to adjust to the environment and, thereby, be able to give a better response to it. 
Family members are also important resources in this confinement moment, but it is important to say that all strategies are possibilities, adjustments and variable tools. They are not unique to all children, therefore, do not be concerned when one of them doesn't work out, or when the answer doesn't come out the way you have planned. It is also in times like these that adults and children reinvent themselves, test themselves and learn how to function differently.

\section{Examples:}

\section{BREATHE DEEPLY!}

IT WILL GO AWAY!

\section{IF IT DOESN'T, BREATHE AGAIN!}
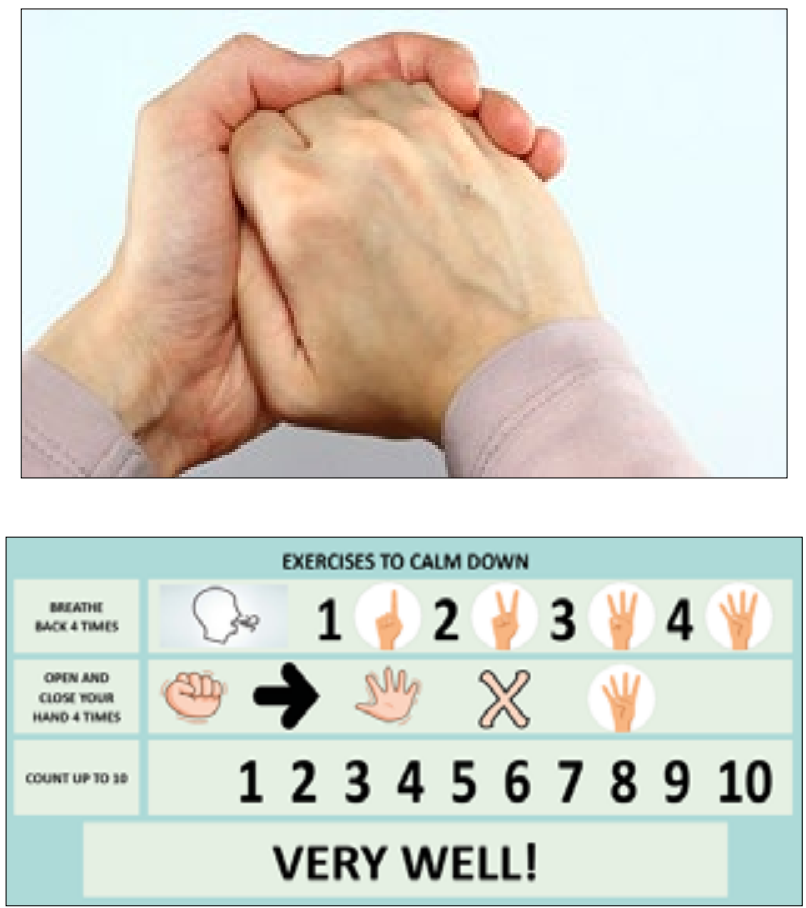

\begin{tabular}{|c|c|c|c|}
\hline & If INSIDE & हुํㅏㄹ & OUTSIDE \\
\hline$\|$ & WEIGHTLIFTING & $\begin{array}{l}60 \\
08\end{array}$ & PLAY SOCCER \\
\hline 能 & DANCE & 武 & GARDENING \\
\hline مرئي & CLIMBING STAIRS & 8 & TAKE A TOUR \\
\hline 8 & YOGA & 象吊 & WALK THROUGH NATURE \\
\hline
\end{tabular}

6 Maintain and Create New Possibilities for the Routine

Tips for creating a task analysis

1. Choose a task with a well-defined beginning, middle and end (for example. setting the table, getting dressed, making the bed);
2. Write down the steps while you do the task or watch another adult doing it;

3. Give step-by-step instructions for another person to try to follow and make sure the steps are clear;

4. Write down the final steps on a paper sheet to guide instructions on teaching the task to your child;

5. If necessary, draw or take pictures from suggestions for each step, to make up as visual schedule reference to your child;

6. Teach the task using the support strategy that best suits your child;

7. Some learners who are easily frustrated can do better with the largest to smallest support strategy, in which you begin giving more support and slowly reduce it. Other students, however, can achieve independence more quickly through the less for higher level support strategy.

Keeping the routine is important, mainly because it offers predictability and decreases anxiety. However, it must be organized and flexible, opened up for changes, new agreements and new learning opportunities. Daily life tasks are important to promote independence and autonomy [23]. Not only right now, but it is always important to keep some routines, such as:

- Sleeping routine: the environment must be pleasant according to each individual's best adaptation, such as: light; temperature; comfortable clothing; massages; story books reading; bathing; and light and distractions avoidance, such as iPads, computers and TV;

- Household chores: help making the bed, picking the toys up, setting the table for the meals; serving pets with water and food; putting items on the closet.

Use Tips:

\begin{tabular}{|l|l|}
\hline $\begin{array}{l}\text { From largest to smallest } \\
\text { support }\end{array}$ & $\begin{array}{l}\text { From smallest to largest } \\
\text { support }\end{array}$ \\
\hline Fully physical & Visual \\
\hline Partially physical & Verbal \\
\hline Model & Gestural \\
\hline Gestural & Model \\
\hline Verbal & Partially physical \\
\hline Visual & Fully physical \\
\hline
\end{tabular}

\begin{tabular}{|c|c|c|c|}
\hline \multicolumn{2}{|r|}{ WeEkr Goals } & \multicolumn{2}{|r|}{ DaIIY TARGETS } \\
\hline 然 & PLAY SOCCER & 骨? & MAKE THE BED \\
\hline & PLAY WITH THE DOG & קֶ? & DRESS UP \\
\hline$(3)$ & RECREATION & 曗合 & HAVE BREAKFAST \\
\hline 요 & GARDENING & 衁 & BRUSH THE TEETH \\
\hline ï & WALK IN THE BACKYARD & (ब9, & STORE THE PAJAMAS \\
\hline & & 曼 & DO TASKS \\
\hline
\end{tabular}


Behavior Analysis technologies involved in this booklet:

- Visual clues;

- Social stories;

- Routine, reward and combined board;

- Task analysis;

- Tips hierarchy;

- Self-management .

\section{Sensory Strategies}

Literature has shown that 45 to $96 \%$ of children with ASD have significant disorders in sensory processing [24,25]. In addition, approximately $14 \%$ to $17 \%$ of school-age children are reported to have difficulties in processing and integrating sensations, affecting their participation in activities of daily living [26].

Such changes affect mainly auditory, tactile, vestibular and proprioceptive systems. Sensory Integration (SI) is a neurological process in which the brain must have the ability to organize and process information coming through different sensory channels, inter-relating and synthesizing it in order to deliver an adequate response [27,28].

Direct Sensory Integration interventions require a structured and well-furnished environment. Some material is peculiar to the use of the occupational therapist, the qualified professional for this intervention. However, it has been possible to draw family members close to the professionals, creating possibilities for SI indirect interventions. When one considers that sensory information affects daily life decisions, that it fuels the brain to ignite its operations, and that it also assists in the creation of a bodily and environmental map, its disorders will generate unadjusted to the environment as well.

By comprehending that sensations lay the foundation for any intended action, it can be understood that sensory disorganization of a child with ASD can occur for several reasons:

- Inability to focus on the received stimulus.

- Failure to filter out irrelevant aspects of the stimulus.

- Failure to fully process the information contained in the stimulus.

When the routine of a child with ASD is being adjusted, or in situations like the social distancing we are experiencing - when there is a significant break in the routine -, it can be considered that the whole gear works in order to create a different response for the environment. So, it becomes common for the family to experience upsetting moments with the child, either due to behavioral changes or sensory searches, both being accentuated in this period. Somehow the child communicates that something is not well.

In this sense, the child is not a passive recipient of sensations; instead, he/she integrates sensations, organizes the information for a future action, reaction or behavior plan, and monitors the plan when executed [29].

Behavioral patterns in ASD children may be related to the level of alertness to a given stimulus and how quickly the children's brain perceives the sensory impulse, reacting to it. Also, behavioral changes can be related to the mode of perception, and not reaction, to sensory stimulation. Thus, their response to the environment is the result of the process.

In relation to children with Sensory Modulation Disorder, if he/she presents as hyper-reactivity to sensory stimuli, a more controlled environment must be provided. On the other hand, if hypo-reactivity to sensory stimuli is noted, the child needs an environment richer in sensory input [30].

Many items that are part of our routine at home can help us create sensory strategies according to the needs of each child. There is no need for a radical change in the environment to offer adequate sensory experiences.

In this way, family members can organize the environment, the home and the routine in order to include sensory strategies as means to increase the child functionality and facilitate his/ her participation in the home routine. In a relaxed way, sensory strategies will aim to make child belong to the environment. In the context of social distancing, home and family members will be instrumental for sensory strategies.

It is worth mentioning that when we refer to sensory strategies as strategies of belonging and as possibilities of indirect intervention, in order that the child keeps functional, it is not to be understood as a direct intervention of Sensory Integration. They are not interchangeable, although homemade mechanisms, games, toys and actions that contemplate the sensory needs of children with ASD are possible in times of social distancing.

It is comprehensible that home routine has its difficulties and obstacles, but it can also bring possibilities that differs from of those of therapy. Often in the house the child feels more comfortable and can allow unusual interactions with the family. The house, as a protected environment, can be the place where the child will take some risks to do different things and create new possibilities. Therefore, it is worth considering some important points when one thinks of inserting sensory strategies for the child self-regulation [31]:

1. Identify the child's intrinsic motivation.

2. Check if the activity is adequate to the child's difficulty level, according to what he/she can perform and his/her needs.

3. Encourage the child whenever he/she tries something new.

4. Assure the child of his/her success in the intended activity. It is important for the child to feel successful, so he/she can engage and keeps engaged in the activity.

5. Keep activities relaxed, without demanding the child to comply with all rules. They often have incredible ideas that can make the game more fun.

6. Be sensitive to the child's subtle signs such as gaze, touch and body movements.

7. Finally, offer pauses to the child. They are extremely 
important so the child can find space and time to respond to the environment.

Cushions, swings, trampolines, pool floats, hammocks, Lycra swings, hearing dampers, balls, moisturizers, sponges, shaving foam, sand tanks, weighted blanket and others can be important features when it comes to sensory strategies. There are also some games that can become a valuable resource at home. Tug of war, pushing heavy objects, playing games in prone position are great ways that might regulate children with deficit in tactile and proprioceptive processing.

Spinning, swinging, balancing and slipping are the favorites playful activities of children with vestibular system disorders.

Multi-stage games, in which the child assembles, creates possibilities and rules for each stage of the game can benefit children who encounter difficulties in motor planning and sequencing of activities.

For child with problems in concentration and activities of fine motor, it is useful to encourage he/she to play games that work out the body globally before doing an activity that requires greater attention and manual ability. Changing the position for a common activity can be a strategy, for example, drawing in prone position, on the knees or on the floor.

The Table relates the use of sensory strategies and their variations in order to address the child's needs and to create an environment that supports the child's functionality at home. Most of all, it is worth mentioning that these are difficult times, demanding adaptations and constant reinvention from the families and therapists. It is necessary to act gently and relieve the demand. Parents should carry on their main task of parenting, using the strategies as means for the child's functioning participation, and not as a burden of therapy. If it did not work one day, that's fine! Try again the next day. Play together and respect the break and the hiding places! They are necessary!

\begin{tabular}{|l|l|l|}
\hline SYSTEMS & $\begin{array}{l}\text { TO CALM } \\
\text { DOWN }\end{array}$ & TO ALERT \\
\hline Visual & $\begin{array}{l}\text { Natural and soft } \\
\text { colors }\end{array}$ & $\begin{array}{l}\text { Vivid and bright } \\
\text { colors; moving } \\
\text { objects in the } \\
\text { direction of the } \\
\text { child's face; } \\
\text { focusing objects } \\
\text { with a lantern; } \\
\text { moving them at } \\
\text { different speeds }\end{array}$ \\
\hline Auditory & $\begin{array}{l}\text { Soft sounds; soft } \\
\text { and slow voice }\end{array}$ & $\begin{array}{l}\text { Sounds with } \\
\text { mixed intensity; } \\
\text { a c e e t u t e d } \\
\text { rhythm and beat; } \\
\text { loud music }\end{array}$ \\
\hline
\end{tabular}

\begin{tabular}{|c|c|c|}
\hline Vestibular & $\begin{array}{l}\text { Rhythmic and } \\
\text { slow swing; } \\
\text { steady movement; } \\
\text { sustained position } \\
\text { of head and neck }\end{array}$ & $\begin{array}{l}\text { D y s h y th m ic } \\
\mathrm{m} \text { o } \mathrm{v} \text { e m e } \mathrm{n} \mathrm{t} \text {; } \\
\text { variations in } \\
\text { speed; change of } \\
\text { head position; } \\
\text { spinning, jumping }\end{array}$ \\
\hline Touch/Pressure & $\begin{array}{l}\text { Deep touch; } \\
\text { weighted blanket; } \\
\text { pressure roll }\end{array}$ & Light touch \\
\hline Oral & $\begin{array}{lr}\text { Constant } & \text { food } \\
\text { temperature } & \text { and } \\
\text { texture } & \end{array}$ & $\begin{array}{l}\text { Variation in food; } \\
\text { acid flavors; } \\
\text { chewing during } \\
\text { activities that need } \\
\text { attention }\end{array}$ \\
\hline Proprioception & $\begin{array}{l}\text { Activities of } \\
\text { r e s i s t a n c e } \\
\text { rhythmic motor } \\
\text { activities }\end{array}$ & $\begin{array}{l}\text { Variable motor } \\
\text { a c t i v i t i e s ; } \\
\text { activities } \\
\text { resistance }\end{array}$ \\
\hline
\end{tabular}

Examples of Sensory Integration Activities

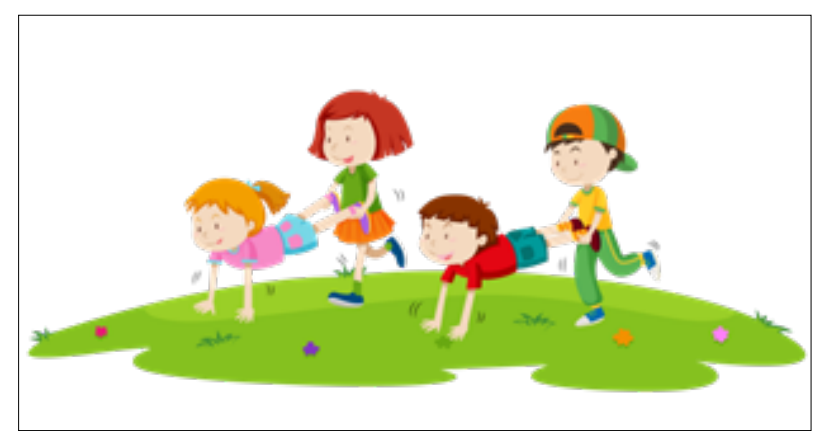

The wheelbarrow walk around the house can be a lot of fun. Motor planning, body weight unloading, and tactile and vestibular proprioceptive inputs are part of this game. The wheelbarrow walk can be a game itself or part of another activity, such as a circuit, a throwing game, or compounding words game. It is all about changing the child's position.

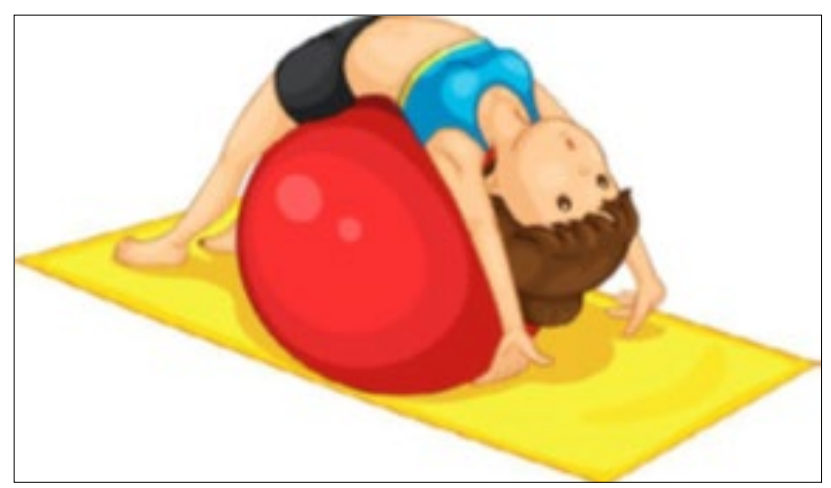

If the child likes the position but has trouble maintaining it for a long time, you can adapt the game, once it is desirable that he/she feels successful in it. You can use an exercise ball as a support, so the child can expand his/her movements and strength until he/she feels confident to sustain the body weight in his/her arms. 


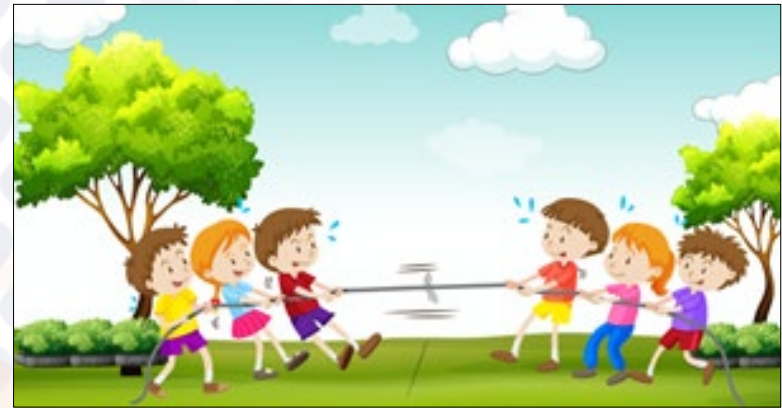

Tug-of-war, alone or accompanied, is the favorite game of those who love to climb and push! One can play it by his own. Children with proprioceptive processing disorders can benefit from this game.

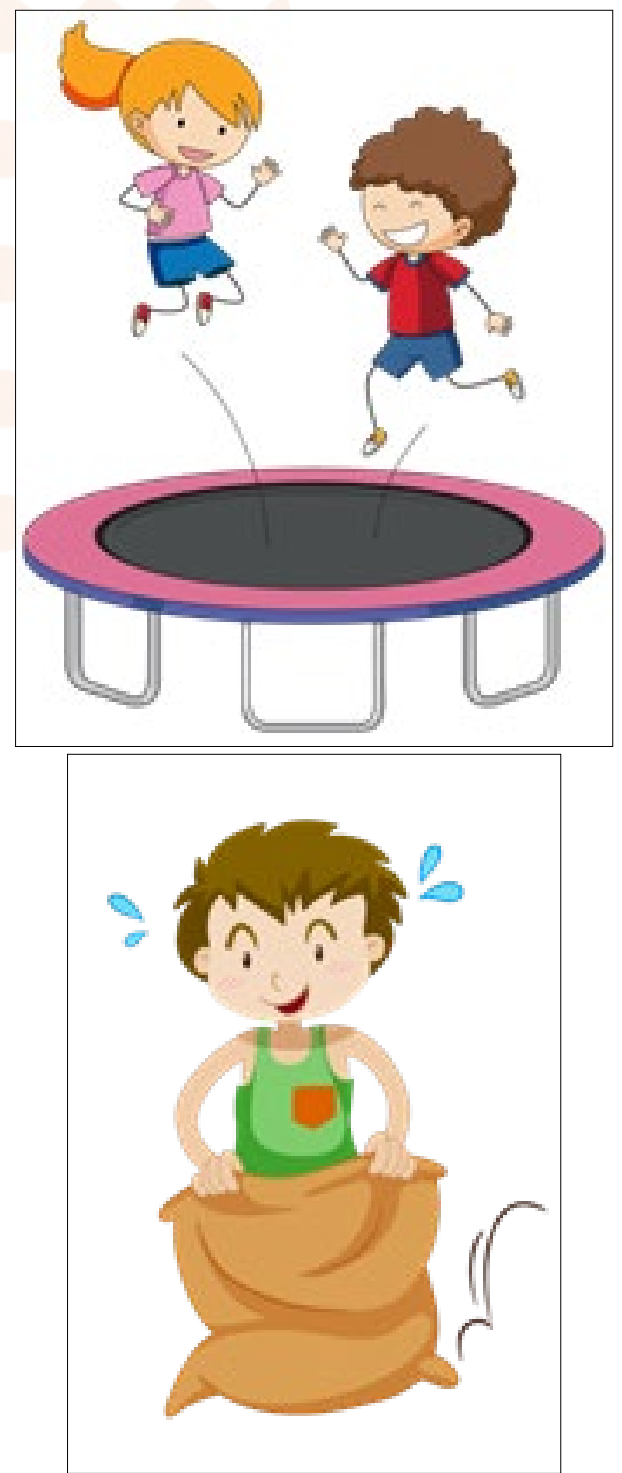

For those who enjoy jumping, jump rope, bag race and trampoline are awesome activities, and guarantee some entertaining time. Those games work out vestibular, proprioceptive and motor planning systems.

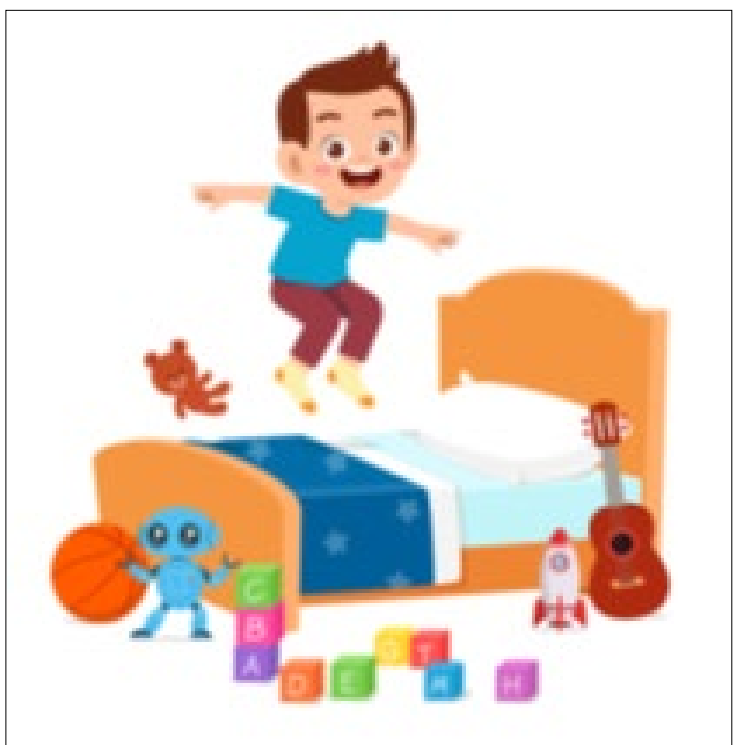

In the absence of a trampoline, jumping on the bed works out the same systems, with similar benefit

For children interested in more radical and resistant movements, it is advisable to allow them to explore new positions. In unusual positions tactile, vestibular and proprioceptive receptors are accessed most effectively. Give them a try!

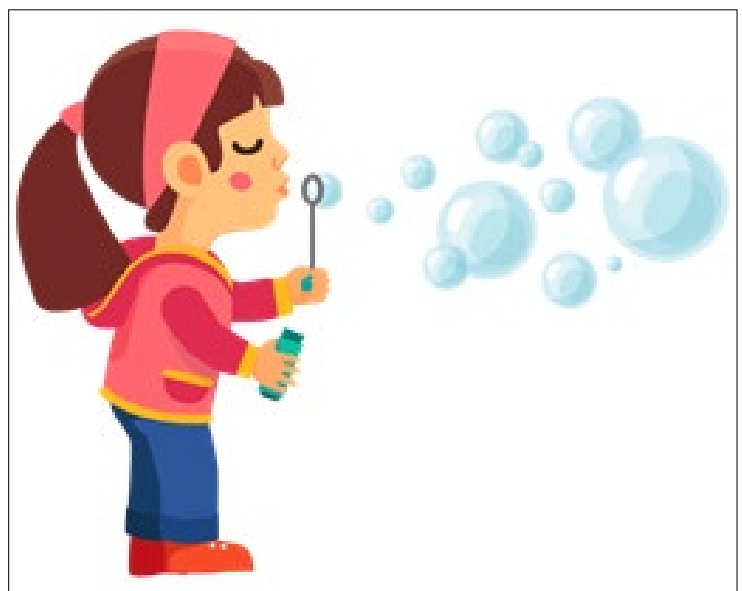

Bubbles captures people's attention in all ages. They are cool not only because they are a visual and motor stimulations, when children try to catch them, but also for the oromotor exercise associated with blowing them.

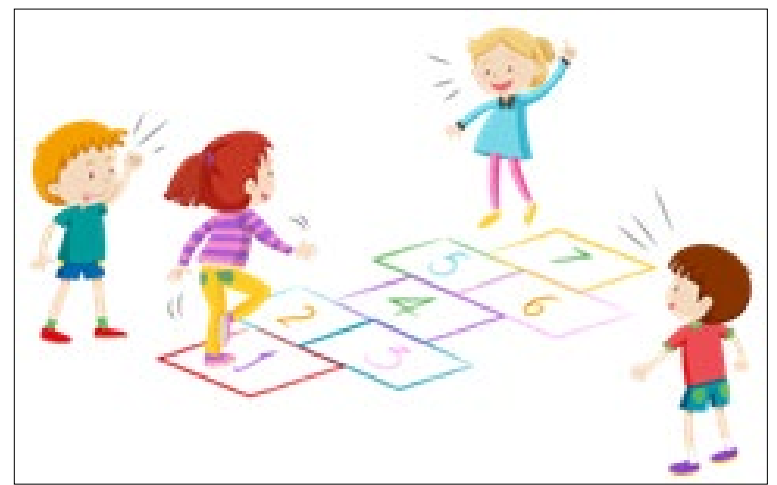


There are many possibilities and activities that explore motor planning. There is a huge gap between thinking about movement and executing it, and this gap is what we call 'motor planning'. The child must have the ability to think about the movement, plan mentally and finally perform. Games like those mentioned above are extremely popular. Children feel challenged and motivated to solve the problems at each stage. It is important that the difficulty level is appropriate for the child's age and skill. The main point is to have a light and fun routine. You don't want to add unwanted feelings on the top of those caused by the social distancing. On the other hand, the activities cannot be uninteresting. The children must realize that you believe in their performance capacity.
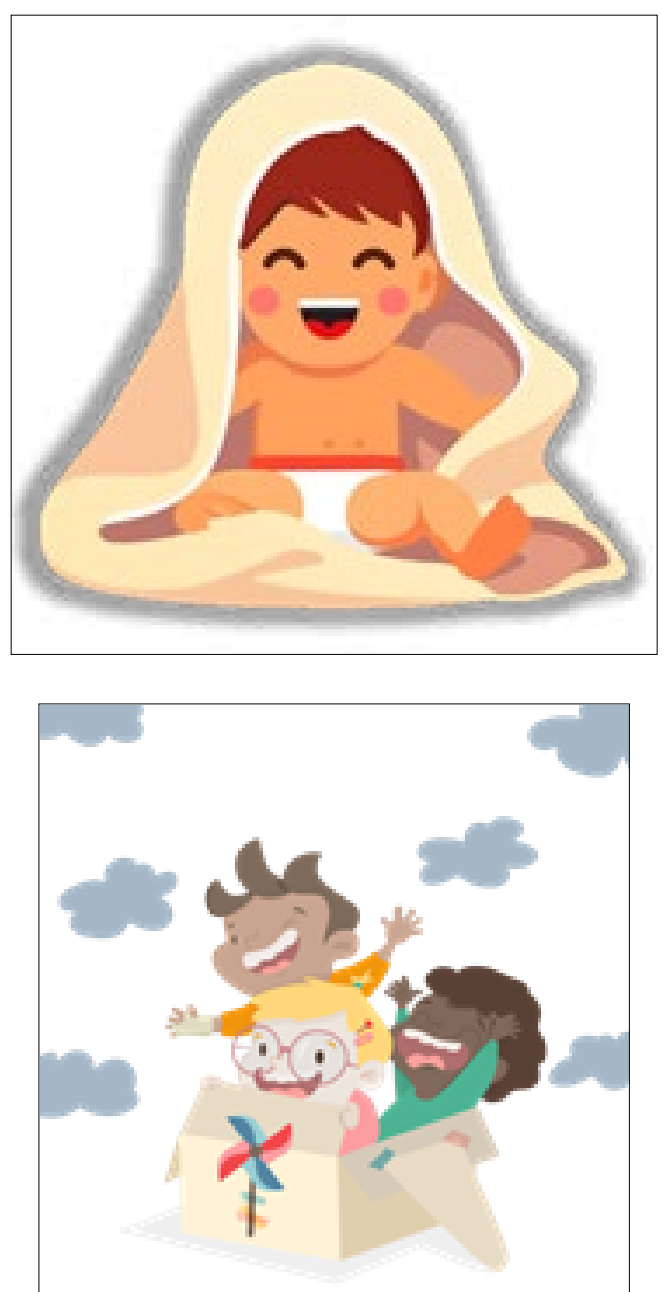

"Packages" activities are recommended for children who like to be put themselves between things, like mattresses, cushions and hugs. This type of space definition enhances their level of attention and activity. Give it a try. Plastic box and laundry basket will do it too!

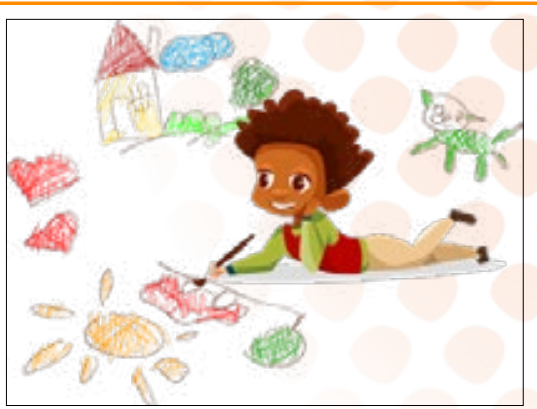

It is common that children who seek movement show a decreased level of attention. Encourage them to do manual or reading activities, or to play board games in unusual positions. The result can be exciting. Even activities that require a higher level of concentration can achieve better results if the child keeps moving around while does it. Exercise balls may be an important asset for those cases.

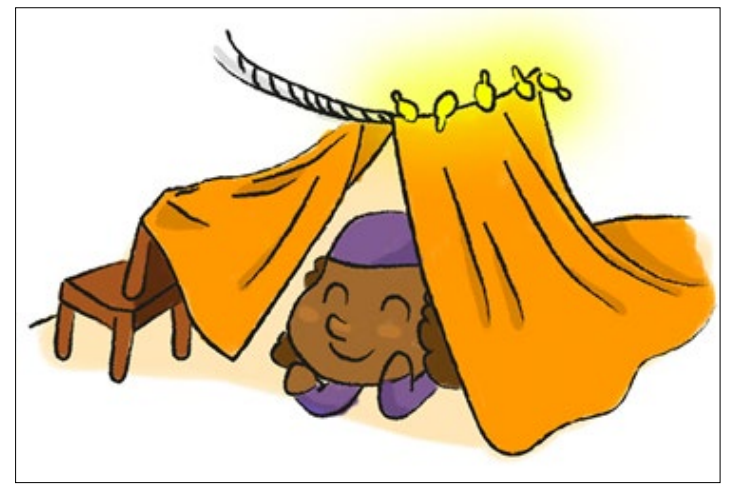

Sometimes it is necessary that children with ASD have a place to hide, like a hut. It can be a sheet or cardboard hut, or a place within the closet. Usually, they need those spaces to reorganize the excess information, and the CNS filters what should have been filtered before they come back to action It is important for the hiding place to be accessible. Sometimes it can be noted that even in a highly enjoyable game, the child feels alerted and looks for the shelter to organize him/herself.

- For climbers on duty, anything works! It can be the mattress leaning on the sofa, or a cardboard on the stairs. These activities intensely work the vestibular and proprioceptive systems, and are useful to calm down overflowing tempers.

- Dining room chairs can become a tunnel in the living room or kitchen. They can be part of a circuit that benefits motor planning and brings a lot of fun.

- You can take your child to a different tour around the house. A sheet or bedspread can become a means of transport. It is interesting to encourage the child to create his own story while it is driven around. Otherwise, you can narrate a situation and a context to him/her, "Look, you are getting in a special car! We will drive by a gas station, so you may have enough energy to reach your destination!" The 'gas station' can be a chair prepared with objects with different textures, such as sponges, textured balls, shaving foam. 'Fill the tank' means rub these objects on the child's body. This walk can be done also with the child in in a different position, like crawling like a soldier. 


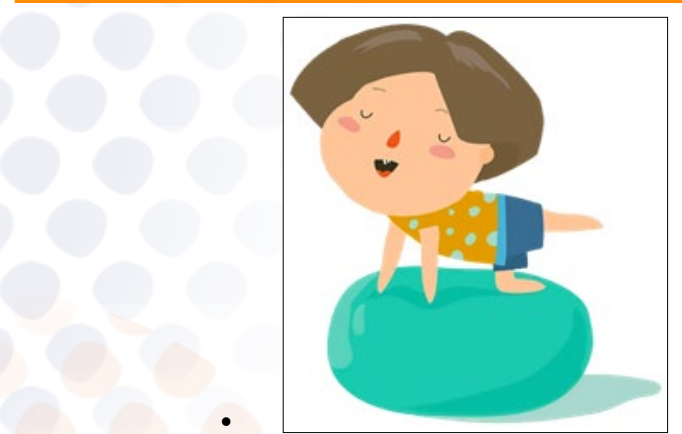

Exercise balls are a powerful resource. They can be used for tactile pressure, to sit, jump, massage.

Vestibular games amuse children and can be quite simple spinning, jumping and balancing. Some children need a higher amount of activity until they feel satisfied with the movement. If you notice this, add some element of resistance in the game, such as jumping, throwing or climbing.

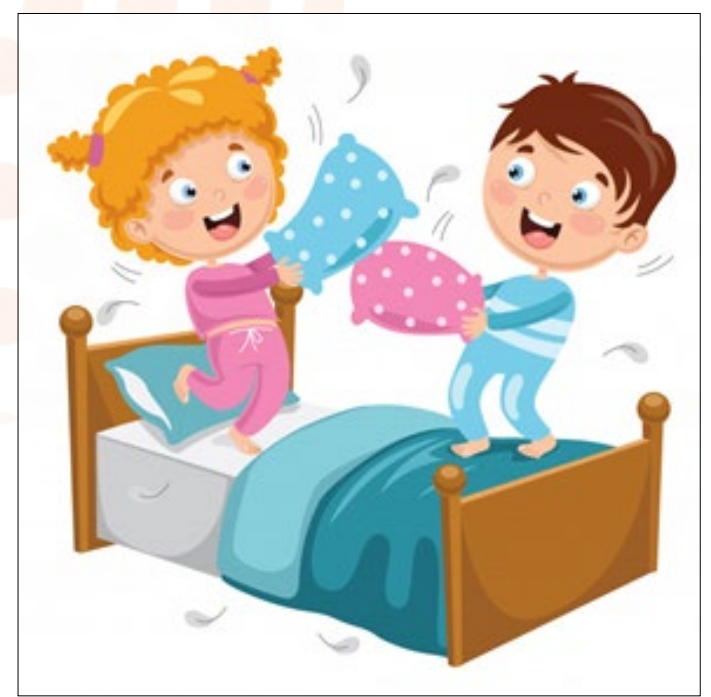

A session of "therapeutic fight" or "pillows squeeze" are also a preferred game of some children with sensory processing disorder. It activates tactile, pressure-sensitive and proprioceptive receptors, and provides a lot of fun for parents and children. If your child likes this kind of contact, preferring tight hugs than light touches, these kind games will be more useful. Children with tactile defensiveness tend to enjoy intense touch activities, since it creates a deeper sensory input. It allows a clearer record of sensory information in comparison to those made of light touches.

Most of tactile sensory activities are part of children's development since birth. However, some children are resistant to such experiences, which is well marked in their behavior by crying, nausea, restlessness and irritability. If your child enjoys it, explore and create activities from these resources, that are infinite. Pasta and rice get colored with food coloring. Sand tank filled with different objects favors fine motor skills. If your child feels uncomfortable with these materials, create comfortable situations for them. For example, if they are playing with toy cars, let them have a foam car wash. If they are playing with farm animals, let them feed the animals with sand or playdough. Tactile exploration materials can also make bathing more fun. You can use different sponges, a foam bathtub and gel balls, transforming the bath in a sea of exploration.

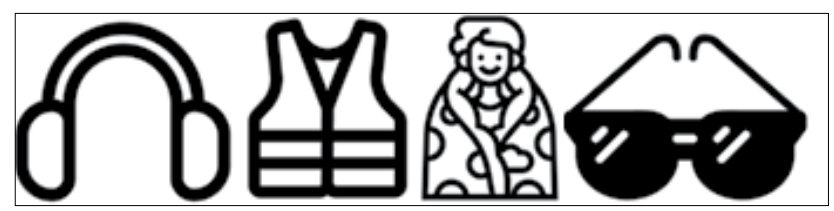

In addition to games, you can use specific resources as sensory strategies, like:

1. Hearing mufflers

2. Weighted vests

3. Weighted blankets

4. Sunglasses.

\section{References}

1. American Psychiatric Association (2013) Diagnostic and statistical manual of mental disorders. 5th ed. Arlington, VA: American Psychiatric Association; 2013.

2. Maenner MJ, Shaw KA, Baio J, et al. (2020) Prevalence of Autism Spectrum Disorder Among Children Aged 8 Years - Autism and Developmental Disabilities Monitoring Network, 11 Sites, United States, 2016. MMWR Surveill Summ 69(No. SS-4): 1-12. DOI: http://dx.doi. org/10.15585/mmwr.ss6904a1

3. Harvard Health Publishing Coronavirus Resource Center, COVID-19 basics. Symptoms, spread and other essential information about the new coronavirus and COVID-19. https://www.health.harvard.edu/diseases-and-conditions/ coronavirus-resource-center

4. Harvard Health Publishing Coronavirus Resource Center, COVID-19 basics. As coronavirus spreads, many questions and some answers. https://www.health.harvard. edu/diseases-and-conditions/coronavirus-resource-center

5. World Health Organization (2019) Coronavirus disease (COVID-19) Pandemic. https://www.who.int/ emergencies/diseases/novel-coronavirus-2019

6. Luyster RJ, Lord C (2012) The language of children with autism. In Bavin EL (ed.). The Cambridge handbook of child language. Cambridge: Cambridge University Press; 2012.

7. Ozonoff S, Iosif AM, Baguio F, Cook IC, Hill MM, Hutman T, Rogers SJ, Rozga A, Sangha S, Sigman M, Steinfeld MB, Young GS (2010) A Prospective Study of the Emergence of Early Behavioral Signs of Autism. J Am Acad Child Adolesc Psychiatry 49(3): 256-66.

8. Sacrey LR, Zwaigenbaum L, Bryson S, Brian J, Smith IM, Roberts W, Szatmari P, Vaillancourt T, Roncadin C, Garon N (2018) Parent and Clinician Agreement regarding Early Behavioral Signs in 12- and 18-Month-Old Infants at-Risk of Autism Spectrum Disorder. Autism Research 2018.

9. Paul R, Wilson KP (2009) Assessing speech, language and communication in Autism Spectrum Disorder. In: Goldstein S, Naglieri JA, Ozonoff S (eds). Assessment of Autism Spectrum Disorder. New York: The Guilford Press; 2009. 
10. Arvigo MC, Saad AG, Signorelli F, Haddad RGC, D'Antino MEF (2018) Autism Spectrum Disorder and communication. In: Amato CAH, Brunoni D, Boggio OS (orgs) Developmental disorders: interdisciplinary studies. São Paulo: Memnon; 2018.

11. Goyos C. ABA (2018) : Teaching speech to people with autism. São Paulo: Edicon; 2018.

12. Perissinoto J, Isotani SM, Tamanaha AC (2017) Child Language Delay Intervention Process. In: Lamônica DAC, Britto DBO. Language Treaty: contemporary perspectives. Ribeirão Preto: Booktoy; 2017.

13. Andrade AA, Oliveira AL, Teixeira IA (2017) Training of parents. In: Walter Camargos Jr et al. (Orgs) Early intervention in autism. Belo Horizonte: Editora Artesã, 1st edition.

14. Bagaiolo L, Pacífico CR (2018) Orientation and training of La FranceDL, Weiss MJ, KazemiE, GerenserJ, DobresJ Multidisciplinary Teaming: Enhancing Collaboration through Incread Understanding. Association for Behavior Analysis International, 2019.

15. LeBlanc LA, Gillis JM (2012). Behavioral interventions for children with autism spectrum disorders. Pediatric Clinics of North America, 59(1), 147-164, xi-xii. https:// doi.org/10.1016/j.pcl.2011.10.006

16. Bird W, Adamo G, Pitini E, Gray M, Jani A (2020) Reducing chronic stress to promote health in adults: the role of social prescriptions and social movements. Journal of the Royal Society of Medicine 113(3): 105.

17. Hayes SC, Smith S (2005) Get out of your mind and into your life: the new acceptance and commitment therapy. Oakland, CA: New Harbinger Publications, Inc.

18. Bondy AS, Frost LA (1994) The picture exchange communication system. Focus on Autistic Behavior 9(3): 1-19. https://doi.org/10.1177/108835769400900301

19. Battaglia D, McDonald ME (2015) Effects of the picture exchange communication system (PECS) on maladaptive behavior in children with autism spectrum disorders (ASD): A review of the literature. Journal of the American Academy of Special Education Professionals.

20. Hedges S, White T, Smith L (2014) Depression in adolescents with ASD (Autism at-a-Glance Brief). Chapel Hill: The University of North Carolina, Frank Porter Graham Child Development Institute, CSESA Development Team.

21. Hedges S, White T, Smith L (2015) Anxiety in adolescents with ASD (Autism at-a-Glance Brief). Chapel Hill: The University of North Carolina, Frank Porter Graham Child Development Institute, CSESA Development Team.

22. Benamou-Shipley, R Lutzker JR, Taubman M (2002) Teaching daily living skills to children with autismo through instructional video modeling. Journal of positive behavior interventions 4 (3): 166-177.

23. Watling R L, Deitz J, White O (2001) Comparison of Sensory Profile scores of young children with and without autism spectrum disorders. American Journal of Occupational Therapy 55 (4): 416-423.

24. Tomchek SD, Dunn W (2007) Sensory processing in children with and without autism: a comparative study using the short sensory profile. American Journal of Occupational Therapy 61 (2): 190-200.

25. Reynolds S, Lane SJ (2008) Diagnostic validity of sensory over-responsivity: A review of the literature and case reports. Journal of autism and developmental disorders 38(3): 516-529.

26. Ayres AJ (1971) Characteristics of types of sensory integrative dysfunction. American Journal of Occupational Therapy 25 (7): 329-334.

27. Ayres AJ, Robbins J (2005) Sensory integration and the child: Understanding hidden sensory challenges. 25th Ed. Los Angeles: Western Psychological Services, 2005.

28. Serrano P (2018) Sensory integration in the child's development and learning. 3rd edition. Lisbon: PapaLetras, 2018.

29. Parham LD, Mailloux Z (2010) Sensory integration. In Case-Smith J, O'Brien JC Occupational therapy for children. 6th Ed. Maryland Heights: Mosby Elsevier 325372.

30. Bundy AC, Lane SJ, Murray EA (2002) Sensory integration: Theory and practice. 2nd Ed. Philadelphia: FA Davis, 2002.
Copyright: (C2020 Fabricia Signorelli Galeti. This is an open-access article distributed under the terms of the Creative Commons Attribution License, which permits unrestricted use, distribution, and reproduction in any medium, provided the original author and source are credited. 